\title{
Pelatihan Dasar Flip-Flop untuk SMA/SMK dan Sederajat
}

\author{
Suci Rahmatia ${ }^{1}$, Indrawan Arifianto ${ }^{2}$ \\ ${ }^{1,2}$ Program Studi Teknik Elektro, Fakultas Sains dan Teknologi, Universitas Al Azhar Indonesia, \\ Komplek Masjid Agung Al Azhar Kebayoran Baru, Jakarta Selatan, 12110 \\ Penulis untuk Korespondensi/E-mail: suci@uai.ac.id
}

\begin{abstract}
Abstrak - Indonesia perlu mempersiapkan masyarakatnya agar tidak terus menerus menjadi konsumen namun menjadi produsen yang bisa bersaing di pasar global. Oleh karena itu, kami mencoba menjawab permasalahan tersebut dengan merangkul para pelajar SMA/SMK dan sederajat agar menyadari betapa pentingnya mempelajari teknologi sedari dini. Langkah awal yang dapat dilakukan adalah melalui pelatihan dasar flip-flop. Pelatihan ini sebagai modal awal membangun sifat kritis terhadap teknologi. Jika kepedulian telah terwujud diharapkan akan membawa perubahan untuk kemajuan IPTEK di Indonesia. Flip flop pada pelatihan ini adalah rangkaian lampu yang dapat menyala secara bergantian atau kedap kedip seperti layaknya lampu hias sehingga bisa memberikan nilai keindahan pada area disekelilingnya. Cara pembuatan rangkaian lampu flip flop ini sangatlah mudah. Namun dibutuhkan ketelitian dan juga ketekunan dalam membuatnya.
\end{abstract}

Kata Kunci - Teknologi, Flip-Flop, Lampu Hias, Seven Segmen

Abstract - Indonesia needs to prepare its society not to continue to be a consumer but a producer that can compete in global market. Therefore, we try to answer the problem by embracing the students of Senior High School / Vocational High School and equal to realize how important to learn technology early on. The first step that can be done is through basic flip-flop training. This training as an initial capital builds a critical nature of technology. If the concern has been realized it is expected to bring changes to the progress of science and technology in Indonesia. Flip flop in this training is a series of lights that can be alternated or alternatively blinking like an ornamental light so that it can give a beauty value in the area around. How to manufacture this flip flop light circuit is very easy. But it takes precision and also diligence in making it.

Keyword - Technology, Flip - Flop, Decorative Lights, Seven Segmen

\section{PENDAHULUAN}

$\mathrm{P}$ opulasi Indonesia yang berjumlah 259.1 juta jiwa dengan spesifikasi aktif menggunakan internet sebanyak 88.1 juta, sosial media 79 juta, dan koneksi handphone 326.3 juta dianggap sebagai surga dunia bagi para pebisnis. Mereka menggunakan media digital ini untuk menjual berbagai produk mulai dari kebutuhan pokok hingga tersier dengan harga yang bersaing. Semua akses pembelian hingga pembayaran memudahkan masyarakat untuk menggunakannya. Sehingga timbul jargon 'internet memudahkan masyarakat'. Namun sayangnya jumlah pelaku bisnis dari
Indonesia sangat minim dikarenakan keterbatasan ilmu pengetahuan dan teknologi. Masyarakat tidak mengetahui cara membuat sebuah produk yang handal, pemasaran produk yang tepat sesuai sasaran dan penguasaan teknologi digital jika ingin menjual secara online. Indonesia perlu mempersiapkan masyarakatnya agar tidak terus menerus menjadi konsumen namun menjadi produsen yang bisa bersaing di pasar global.

Oleh karena itu, kami mencoba menjawab permasalahan tersebut dengan merangkul para pelajar SMA/SMK dan sederajat agar menyadari betapa pentingnya mempelajari 
teknologi sedari dini. Langkah awal yang dapat dilakukan adalah melalui pelatihan dasar robot flip-flop. Pelatihan ini sebagai modal awal membangun sifat kritis terhadap teknologi. Jika kepedulian telah terwujud diharapkan akan membawa perubahan untuk kemajuan IPTEK di Indonesia.

Tujuan dari pengabdian masyarakat ini antara lain adalah sebagai berikut :

a. Mengenalkan dasar-dasar robotika sederhana dan flip-flop.

b. Membangun apresiasi pelajar dalam teknologi.

c. Memanfaatkan dan menerapkan hasil-hasil IPTEK untuk pemberdayaan masyarakat, terutama untuk pelajar SMA/SMK dan sederajat sehingga dapat meningkatkan inovasi, pengetahuan, dan keterampilan.

d. Menyebarluaskan IPTEK yang didapat dari hasil penelitian untuk meningkatkan kualitas sumber daya manusia, kesejahteraan dan kemajuan masyarakat.

\section{PEMBUATAN MODUL}

Tahap pertama dalam pengabdian masyarakat ini adalah menyediakan modul sebagai buku panduan. Isi dari modul ini adalah ulasan tentang rangkaian sederhana flip flop, alat dan bahan, dan langkah-langkah pembuatan. Rangkaian flip flop adalah lampu yang dapat menyala secara bergantian, alias kedap kedip seperti layaknya lampu hias sehingga bisa memberikan nilai keindahan pada area disekelilingnya. Cara pembuatan rangkaian lampu flip flop ini sangatlah mudah. Namun dibutuhkan ketelitian dan juga ketekunan dalam membuat rangkaian nya.

Cara membuat rangkaian flip flop sederhana:

1. 4 buah lampu LED, usahakan dengan warna yang berbeda

2. Resistor sebanyak 2 buah dengan nilai hambatan $470 \mathrm{ohm}$

3. Resistor sebanyak 2 buah dengan nilai hambatan $100.000 \mathrm{ohm} / 100 \mathrm{~K}$ ohm

4. Elektrolit condensator/Elko dengan nilai 10uF dan tegangan kerja 16 Volt

5. Transistor dengan seri 2 N3904. Apabila sulit menemukan transistor seri tersebut, anda bisa menggunakan alternatif transistor seri BC457.
6. Sumber daya listrik dengan ukuran tegangan 6 sampai dengan 12 volt. Sumber tagangan tersebut bisa anda dapatkan dengan memanfaatkan batu baterai. Apabila ingin berhemat, maka anda bisa menggunakan adaptor dengan range tergangan antara 6-12 volt.

7. IC 555 sangat banyak dijumpai sebagai komponen utama pewaktu (timer) dan pembangkit pulsa (pulse generator).

8. Seven Segmen adalah komponen Elektronika yang dapat menampilkan angka desimal melalui kombinasikombinasi segmennya.

9. Kapasitor (Capacitor) atau disebut juga dengan Kondensator (Condensator) adalah Komponen Elektronika Pasif yang dapat menyimpan muatan listrik dalam waktu sementara dengan satuan kapasitansinya adalah Farad.

10. Unit solder lengkap dengan timahnya.

11. Papan PCB yang sudah dibuat pola terlebih dahulu.

Gambar 1 memperlihatkan simulasi rancangan skematik robot flip flop yang akan dibuat.

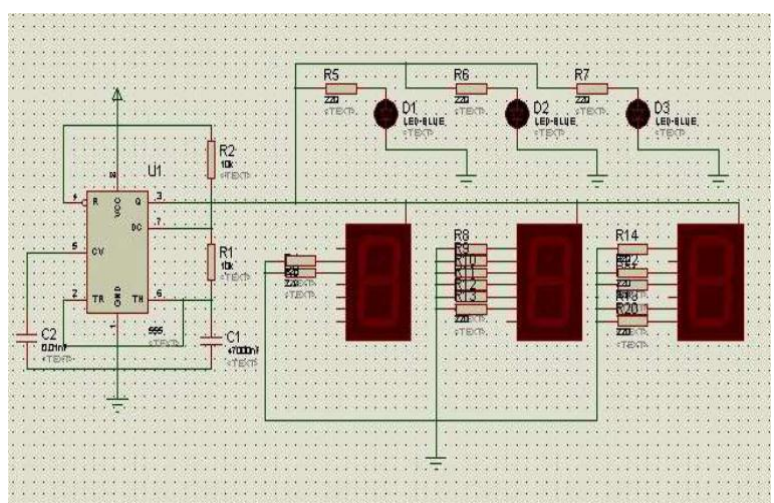

Gambar 1. Simulasi rancangan skematik flip flop

Gambar 2. memperlihatkan rancangan skematik robot flip flop yang akan dibuat.

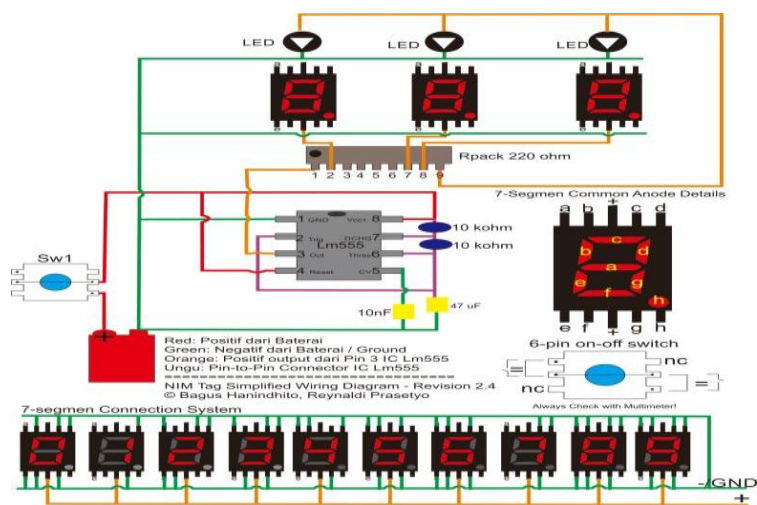

Gambar 2. Contoh rancangan skematik flip flop 
Gambar 3. memperlihatkan prediksi hasil akhir rancangan flip flop yang akan dibuat.

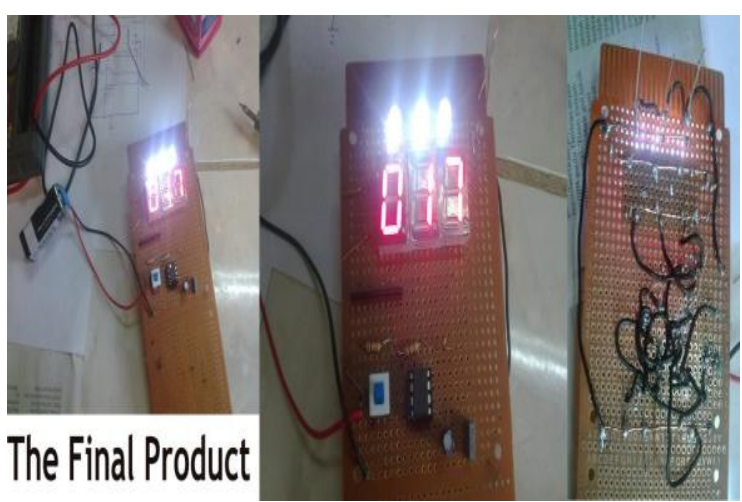

Gambar 3. Rancangan flip flop

\section{LAPORAN KEGIATAN}

Alhamdulillah pelatihan flip flop ini berlangsung dengan sukses dan pesertanya cukup antusias. Pelatihan ini dilaksanakan pada:

Hari/tanggal : Jumat, 2 Juni 2017

Waktu $\quad: 13.00-17.30$ (lanjut buka puasa bersama)

Tempat : Ruang Amphiteater 317 A

Berikut adalah foto-foto kegiatannya:

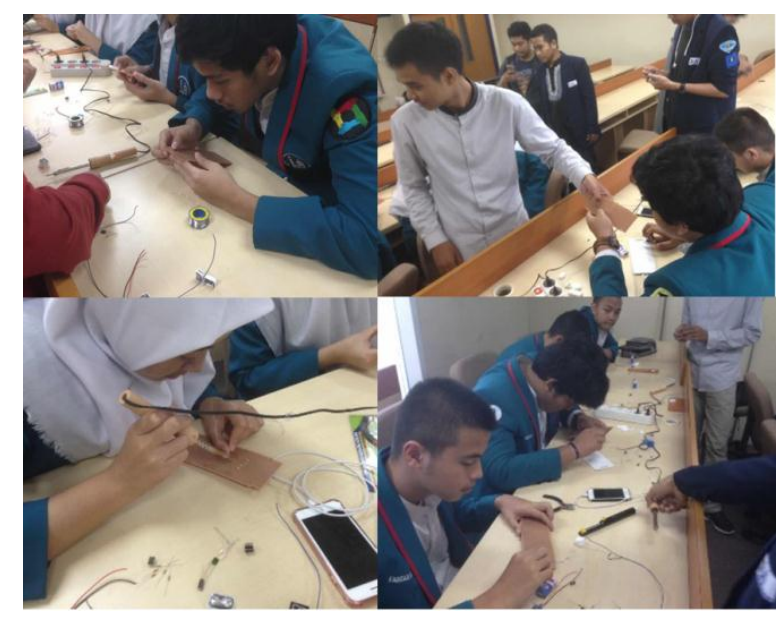

Gambar 4. Siswa sedang merangkai dan menyolder di PCB

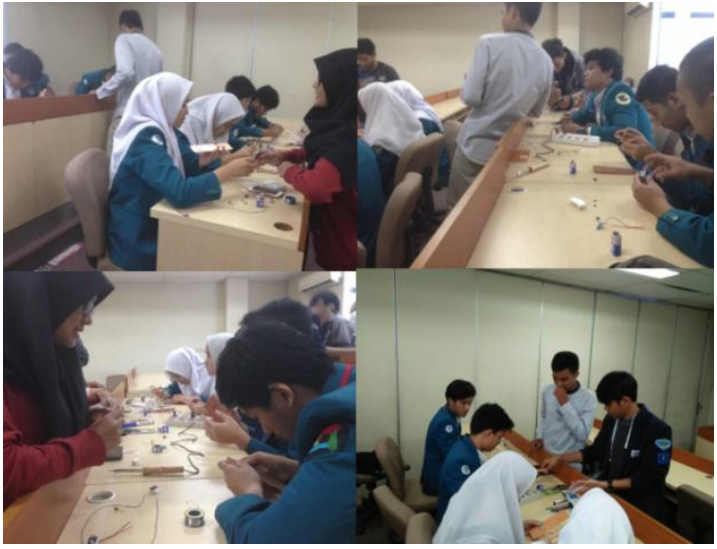

Gambar 5. Mahasiswa setia mendampingi siswa

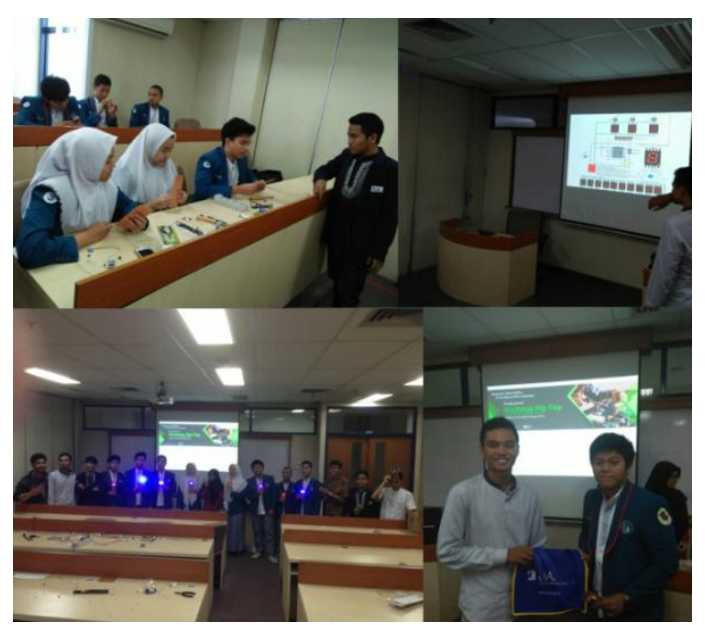

Gambar 6. Pemberian Marchandise dan foto bersama

\section{KESIMPULAN}

Pengabdian masyarakat ini diharapkan dapat memberikan kontribusi yang bermanfaat bagi masyarakat, terutama yang menjadi subjek dalam pengabdian masyarakat. Melalui kegiatan ini diharapkan memberikan dampak positif bagi kehidupan siswa SMA/SMK dan sederajat. Sehingga di masa depan mereka memiliki hidup yang lebih baik dan dapat berguna bagi agama, masyarakat, dan negara.

\section{DAFTAR PUSTAKA}

[1] http://wearesocial.com/uk/specialreports/digital-in-2016, (Diakses pada tanggal 10 November 2016)

[2] http://elektronika-dasar.web.id, (diakses pada tanggal 12 November 2016)

[3] http://playwithrobots.com, (diakses pada tanggal 16 November 2016) 